\title{
MECANISMOS DE TRANSPORTE E DEPOSIÇÃO DOS CONGLOMERADOS DA FORMAÇÃO MARIZAL (CRETÁCEO INFERIOR) NA BACIA DO RECÔNCAVO, BAHIA, BRASIL.
}

\author{
CARLOS CÉSAR UCHOA DE LIMA* GERALDO DA SILVA VILAS BOAS**
}

\begin{abstract}
TRANSPORT AND DEPOSITION MECHANISM OF CONGLOMERATES OF THE MARIZAL FORMATION (LOWER CRETACEOUS) IN THE RECÔNCAVO BASIN, BAHIA, BRAZIL. The conglomerates of the basal portion of the Marizal Formation (Lower Cretaceous), outcropping at the region of Camaçari-BA, Recôncavo Basin, have been subdivided into two groups: massive and stratified conglomerates. The massive conglomerates are represented by three lithofacies: 1. lithofacies Cmc-clast supported massive conglomerates, deposited as pseudoplastic debris flows, characterized by low elastic limit, and by the absence of ngid plug. In this type of debris flow clasts support mechanisms are turbulence and dispersive pressure; 2 . lithofacies Cma-massive conglomerates supported by a sandy matrix. This facies is intimately associated with lithofacies $\mathrm{Cmc}$. Its deposition was promoted by pseudoplastic debris flows more dilute than in the case of lithofacies Cmc, presenting a smaller clast concentration and a major amount of sand and water during transport; 3. lithofacies Cmf-massive conglomerates supported by fine grained sediments, deposited as true debris flows, in which clasts are supported by the cohesiveness of the mixture water-sediment (matrix), by the buoyance forces arising by density contrast between major clasts and matrix, and by the increase in pore pressure resulting from the weight of the sedimentary particles transferred to the water. The stratified conglomerates are represented by the lithofacies Cec (clast-supported stratified conglomerates) and Cem (matrix supported stratified conglomerates). They were deposited as traction carpets, characterized by a bipartitioning of the flow into a basal layer in which clast are highly concentrated and an upper layer less viscous and more turbulent.
\end{abstract}

Keywords: Sedimentary processes, Conglomerates, Marizal Formation.

\begin{abstract}
RESUMO Os conglomerados pertencentes à porção basal da Formação Marizal (Cretáceo Inferior), aflorantes na região de Camaçari-BA, na Bacia do Recôncavo, foram separados em dois grupos: os conglomerados maciços e os estratifícados. Os primeiros são representados por três litofácies, a saber: 1 . litofácies Cmcconglomerados maciços suportados por clastos, depositada por fluxos de detritos pseudoplásticos, caracterizados por possuírem um baixo limite elástico, pela ausência de um embolo rígido e por promoverem a sustentação dos clastos por pressão dispersiva e turbulência; 2 . litofácies Cma-conglomerados maciços suportados por matriz arenosa, que ocorre intimamente associada à litofácies $\mathrm{Cmc}$, cuja deposição foi promovida por fluxos de detritos pseudoplásticos mais diluídos de que no caso da litofácies $\mathrm{Cmc}$, diferindo destes por uma menor concentração de clastos e maior quantidade de areia e água, durante o transporte; 3. litofácies Cmf-conglomerados maciços suportados por finos, que é produto deposicional de fluxos de detritos verdadeiros, em que os clastos são suportados pela coesão da mistura água-sedimento (matriz), pelo empuxo gerado pelo contraste de densidade entre os clastos maiores e a matriz, e pelo aumento da pressão de poro ocasionado pelo peso que esses grãos transferem para a água. Os conglomerados estratifícados, representados pelas litofácies Cecconglomerados estratificados suportados por clastos e Cem-conglomerados estratifícados suportados pela matriz, foram depositados por tapetes de tração, caracterizados por uma bipartição do fluxo, em um camada basal altamente concentrada em clastos e uma camada superior turbulenta e menos viscosa.
\end{abstract}

Palavras-chaves: Processos sedimentares, Conglomerados, Formação Marizal.

INTRODUÇÃO Diversos estudos sobre depósitos conglomeráticos têm sido feitos, na tentativa de elucidar quais os mecanismos de transporte responsáveis pela deposição dos mesmos. Para conglomerados maciços, por exemplo, Middleton \& Hamptom (1976) utilizam o termo "fluxo de detritos" para sedimentos cascalhosos movendo-se declive abaixo por ação da gravidade e os colocam como um dos quatro membros finais de fluxos gravitacionais de sedimentos. Mais recentemente, Shultz (1984) subdivide os fluxos de detritos em quatro regimes diferentes, levando em consideração a concentração de clastos em relação a matriz, o tipo de matriz e as estruturas sedimentares preservadas nos seus produtos deposicionais. Para conglomerados fluviais, Todd (1989) destaca a importância do mecanismo de transporte denominado tapete de tração, descrito anteriormente para turbiditos (Lowe 1982), e propõe a terminologia de "inundações de alta magnitude" para depósitos resultantes desses tapetes conduzidos pela corrente.
Na parte sul da Bacia do Recôncavo ocorrem depósitos amalgamados de conglomerados pertencentes à base da Formação Marizal (Cretáceo Inferior) (Viana et al 1971). De acordo com Gignone (1978), Lima \& Vilas Boas (1990) e Lima (1991), essa formação constitui uma seqüência sedimentar essencialmente terrígena, depositada por sistemas fluviais entrelaçados, associados a leques aluviais. $\mathrm{Na}$ Bacia do Recôncavo, a Formação Marizal tem ocorrência restrita à região de Camaçari - Dias D'Avila e circunvizinhanças (Fig. 1), repousando discordantemente sobre a Formação São Sebastião (Cretáceo Inferior) (Viana et al. 1971). Os corpos conglomeráticos são encontrados principalmente na parte sul da área de ocorrência da formação, sendo que, no restante da mesma, predominam litofácies psamíticas, com ocorrências subordinadas de lamitos.

Os objetivos do presente trabalho incluem a individualização e a caracterização das diferentes litofácies conglomeráticas que compõem a Formação Marizal na sua área de 


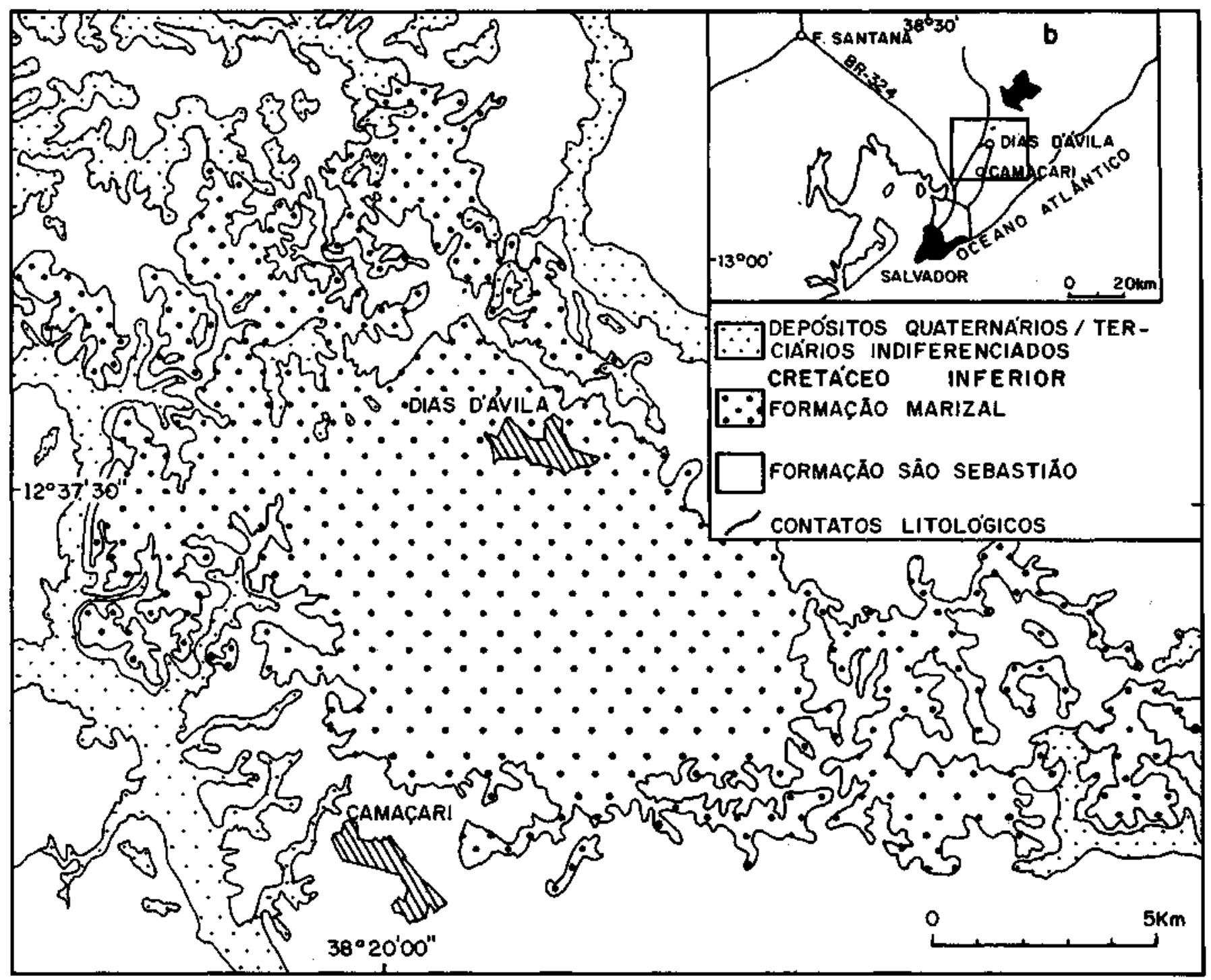

Figura 1 - Mapa geológico simplificado da área

Figure 1 - Simplified geologic map of the area

ocorrência na Bacia do Recôncavo, bem como a definição dos diferentes mecanismos de transporte, responsáveis pela deposição das unidades cascalhosas.

DESCRIČÃO E,INTERPRETAÇÃO DAS LITOFÁCIES CONGLÔMERÁTICAS Os depósitos conglomeráticos foram divididos em conglomerados maciços, dos quais fazem parte as litofácies Cmc, Cma e Cmf, e conglomerados estratificados, subdivididos nas litofácies Cec e Cem (Tab. 1). O sistema de codificação dessas litofácies foi adaptado a partir do trabalho de Miall (1978). No campo, a granulometria dos sedimentos foi determinada com o auxílio de uma régua (fração cascalhosa) ou através de um padrão impresso (areia e lama) (Lindholm 1987). No laboratório, a análise granulométrica foi efetuada por peneiramento (areia) e pipetagem (lama). A classificação granulométrica dos sedimentos foi feita de acordo com o trabalho de Tanner (1969). Para as determinações de arredondamento e esfericidade tomou-se por base a escala visual de Powers (1953).

Conglomerados Maciços LITOFÁCIES Cmc-CONGLOMERADOS MACIÇOS SUPORTADOS POR CLASTOS Os conglomerados que compõem essa litofácies (Prancha 1A) mostram uma ampla distribuição no tamanho dos grãos, que inclui desde granules até matacões. Calhaus predominam e, juntamente com os seixos, formam cerca de $80 \%$ do total de cascalhes. Os clastos variam de angulosos a bem arredondados, sendo compostos principalmente por quartzo, feldspato e rochas quartzo-feldspáticas que, juntos, perfazem de 70 a $90 \%$ do total de grãos cascalhosos. Secundariamente, aparecem clastos de siltitos e lamitos. Além desses, foram também observados fragmentos de quartzito e de rochas ígneas de composição básica, em quantidades quase sempre inferiores a $1 \%$, raramente ultrapassando a $5 \%$ do total de fenoclastos. A matriz é relativamente escassa, ocorrendo em quantidades inferiores a $10 \%$ do total da rocha. Ela é predominantemente arenosa, podendo conter até $5 \%$ de lama.

Os leitos conglomeráticos individuais apresentam geometria em cunha, canal ou tabular. Os corpos amalgamados podem atingir até $7 \mathrm{~m}$ de espessura e várias dezenas de metros de extensão lateral. Os contatos entre as camadas de conglomerados são bruscos e podem ser evidenciados por superfícies regulares e contínuas que se apresentam, por vezes, leve a fortemente côncavas para cima. Em alguns casos, intercaladas entre os leitos de conglomerado, aparecem camadas lenticulares de arenitos, compostos por quartzo e feldspato caulinizado. Essas camadas possuem 
Tabela 1 - Litofácies conglomeráticas da Formação Marizal na Bacia do Recôncavo Table 1 - Conglomeratic lithofacies of the Marizal Formation in the Recôncavo Basin

\begin{tabular}{|c|c|c|c|}
\hline $\begin{array}{l}\text { código de } \\
\text { fácies }\end{array}$ & litofacies & estruturas sedimentares & interpretaçăo \\
\hline Cme & $\begin{array}{l}\text { cascalhos maciços suportados por } \\
\text { clastos. }\end{array}$ & estruturas canalizadas, imbricaçẵo. & $\begin{array}{l}\text { depositos de fluxos de detritos } \\
\text { pseudoplásticos. }\end{array}$ \\
\hline Cma & $\begin{array}{l}\text { cascathos macicos suportados por } \\
\text { matriz arenosa. }\end{array}$ & $\begin{array}{l}\text { estruturas canalizadas, imbricaçăo, } \\
\text { gradaçto. }\end{array}$ & $\begin{array}{l}\text { depósitos de fluxos de detritos } \\
\text { pseudoplásticos mais diluf́dos. }\end{array}$ \\
\hline $\mathrm{Cmf}$ & $\begin{array}{l}\text { cascalhos maciços suportados por } \\
\text { matriz lamosa. }\end{array}$ & imbricação. & $\begin{array}{l}\text { depositos de fluros de detritos } \\
\text { verdadeiros. }\end{array}$ \\
\hline $\mathrm{Cec}$ & $\begin{array}{l}\text { cascalhos estratificados suportados } \\
\text { por clastos (bimodais). }\end{array}$ & $\begin{array}{l}\text { acamamento horizontal, gradaçăa, } \\
\text { imbricaçăo. }\end{array}$ & $\begin{array}{l}\text { depositos de tapetes de tração } \\
\text { (barras longitudinais). }\end{array}$ \\
\hline Cem & $\begin{array}{l}\text { cascalhos estratificados suportados } \\
\text { por matriz (polimodais). }\end{array}$ & $\begin{array}{l}\text { acamamento horizontal, laminaçăo } \\
\text { de baixo ângulo, imbricação, } \\
\text { gradação. }\end{array}$ & $\begin{array}{l}\text { depósitos de tapetes de tração } \\
\text { mais diluídos (barras longitudinais). }\end{array}$ \\
\hline
\end{tabular}

geometria canalizada e evidenciam uma laminação interna que é paralela com a superfície limitante inferior.

Muitos clastos apresentam-se imbricados, sendo a imbricação do tipo $a(p) a(i)$ (eixo $a$ paralelo à direção do fluxo e imbricado) mais comum do que a do tipo $a(t) b(i)$ (eixo $a$ transversal à direção do fluxo e eixo $b$ imbricado) (Harms et al. 1975). Clastos excepcionalmente grandes, isolados, bem como clastos com eixo maior disposto na vertical, aparecem comumente. Os primeiros podem ocorrer em qualquer parte das camadas, os últimos restringem-se às partes mediana e superior. Existe uma nítida relação entre a espessura máxima das camadas e o tamanho máximo dos grãos. O resultado obtido a partir de 49 medidas efetuadas, utilizando-se a metodologia proposta por Bluck (1967), mostra um coeficiente de correlação entre esses dois parâmetros de 0,75 (Fig. 2A).

Diversos pesquisadores (Steel 1974, Larsen \& Steel 1978, Lewis et al. 1980, Glõppen \& Steel 1981, Nemec \& Steel 1984) têm estudado depósitos semelhantes à litofácies Cmc da Formação Marizal, considerando-os como produto de deposição por fluxos de detritos. Dentre as características principais desta litofácies que conduzem a essa interpretação, estão a natureza maciça dos estratos, o pobre selecionamento dos clastos, com alguns deles possuindo tamanho excepcionalmente grande, ou com seus eixos maiores dispostos na vertical, e a forte correlação entre o tamanho máximo dos grãos e a espessura máxima das camadas. Por outro lado, o formato canalizado das camadas e a pequena quantidade de argila na matriz desses conglomerados são evidências que se contrapõem à interpretação de deposição pelos chamados fluxos de detritos verdadeiros, conforme definidos por Middleton \& Hamptom (1976). Em realidade, o conjunto de feições exibidas pela litofácies $\mathrm{Cmc}$ é característico de depósitos formados por fluxos de detritos pseudoplásticos (Shultz 1984). Fluxos desse tipo são caracterizados por possuírem um baixo limite elástico devido ao conteúdo de água relativamente elevado (baixa coesão), fazendo com que a componente do limite elástico seja quase que exclusivamente devida ao atrito. Outra característica dos mesmos, é a ausência, ou a presença bastante reduzida, do embolo rígido que é comumente observado nos fluxos de detritos verdadeiros. Por serem bastante diluídos, os fluxos de detritos pseudoplásticos possuem baixa resistência da matriz, insuficiente para sustentar os clastos. Desse modo, os principais mecanismos de sustentação desses últimos são a pressão dispersiva, que atua mais efetivamente nos locais de maior concentração dos clastos, e a turbulência, que se desenvolve nos estágios em que a velocidade do fluxo é mais alta. A imobilização tixotrópica do fluxo (deposição) ocorre por "congelamento friccional" ("frictional freezing"), tendo em vista a baixa coesão da matriz e a pequena porcentagem da mesma com relação aos clastos maiores (Lowe 1982).

LITOFÁCIES Cmc-CONGLOMERADOS MACIÇOS SUPORTADOS POR MATRIZ ARENOSA Essa litofácies (Prancha IB) é constituída principalmente por seixos e caIhaus arredondados, de baixa a média esfericidade, com composição semelhante à litofácies $\mathrm{Cmc}$, descrita anteriormente. A matriz é mal selecionada, variando de areia fina a grossa, com argila aparecendo esporadicamente, em quantidade sempre menor do que $5 \%$. A porcentagem de matriz com relação aos cascalhos, varia entre 20 e 50\% aproximadamente, sendo que em alguns locais esse valor pode ultrapassar aos 50\%. As camadas dos conglomerados pertencentes à litofácies $\mathrm{Cmc}$ têm espessura máxima de $1 \mathrm{~m}$ e dispõem-se em canais ou em lobos, não possuindo estratificação interna definida, exceto gradação inversa na base de algumas delas. Os contatos entre esses estratos são bruscos, com o limite inferior apresentando geralmente concavidade voltada para cima. A fábrica, bem desenvolvida, exibe imbricação tanto do tipo $a(\mathrm{p}) a(\mathrm{i})$ (mais comum), como do tipo $a(\mathrm{t}) b(\mathrm{i})$, ambas com sentido das paleocorrentes variando entre $\mathrm{N} 335^{\circ}$ e $\mathrm{N} 10^{\circ}$. A espessura máxima das camadas e o tamanho máximo dos grãos têm um coeficiente de correlação de 0,71 (Fig. 2B), que mostra o estreito relacionamento entre esses dois parâmetros.

Apesar dos conglomerados da litofácies Cma diferirem em alguns aspectos com relação aos da litofácies $\mathrm{Cmc}$, quais sejam, o melhor desenvolvimento da fábrica (imbricação), a ausência de fragmentos muito grandes isolados ou de clastos com eixo maior na vertical e, principalmente o fato de serem suportados pela matriz, muitas são as semelhanças entre os mesmos, evidentes quando se comparam as descrições de ambos. Além dessas semelhanças, as litofácies Cma e Cmc ocorrem intimamente associadas. Esses aspectos, aliados à forte correlação entre a espessura máxima das camadas e o tamanho máximo dos grãos, foram determinantes para que se interpretasse a litofácies Cma como sendo transportada por fluxos de detritos de comportamento provavelmente pseudoplástico. Esses fluxos se diferenciariam daqueles que depositaram a litofácies $\mathrm{Cmc}$, por possuírem viscosidade e limite elástico mais baixos, como conseqüência de uma menor concentração de clastos e uma quantidade proporcionalmente maior de água e areia, resultando na formação de depósitos com clastos suportados por abundante matriz arenosa. Os mecanismos de sustentação 

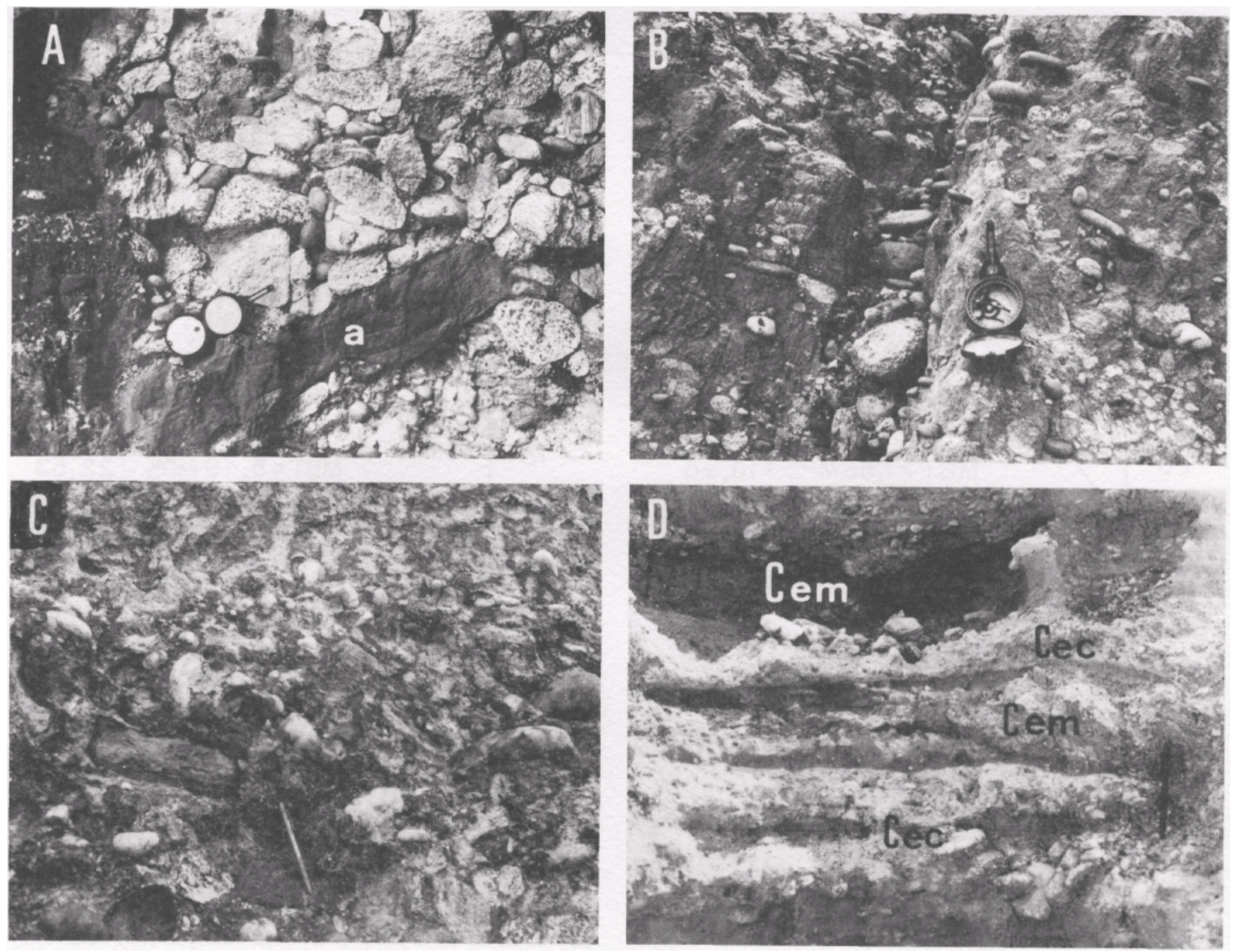

Prancha 1 -A. Litofácies Cmc-conglomerados maciços suportados por clastos. Observar clasto com tamanho excepcionalmente grande (a); B. Litofácies Cma-conglomerados maciços suportados por matriz arenosa. Os clastos apresentam-se imbricados; $\boldsymbol{C}$. Litofácies Cmf-conglomerado s maciços suportados por finos; D. Litofácies Cec-conglomerados estratificados suportados por clastos e Cem-conglomerados maciços suportados por matriz, a erosão diferencial permite uma melhor distinção entre as litofácies

Plate 1 - A. Lithofacies Cmc-clast supported massive conglomerates. Please note clast with exceptionally large size (a); B. Lithofacies Cma-massive conglomerates supported by a sandy matrix. The clasts show imbrication; C. Lithofacies Cmf-massive conglomerates supported by fine grained sediments; D. Lithofacies Cec-clast supported stratified conglomerates and Cem-matrix supported stratified conglomerates. Differential erosion allows a betterdistinction between lithofacies

dos clastos durante o transporte são os mesmos descritos para a litofácies Cmc. A pressão dispersiva fica caracteristicamente confinada à porção basal do fluxo, onde é desenvolvida a gradação inversa. A turbulência passa a atuar de modo mais efetivo como mecanismo de sustentação dos clastos, já que nesses fluxos a velocidade é relativamente maior.

LITOFÁCIES Cmf-CONGLOMERADOS MACICOS SUPORTADOS POR FINOS Essa litofácies (Prancha 1C) é constituída por cascalhes com granulometria variando de granules a calhaus, na maioria arredondados, de esfericidade baixa a média, compostos por quartzo e rochas quartzofeldspáticas. A matriz é argilo-arenosa e varia em quantidade, de cerca de 20 a $70 \%$. Embora os dados obtidos em laboratório tenham fornecido um valor médio de $45 \%$ de lama na matriz, as observações de campo mostraram uma grande variação da quantidade de finos presentes na mesma. Em alguns locais, sobretudo no topo das camadas, os clastos se suportam, mas isso é pouco comum. No mais das vezes, eles se distribuem de maneira aleatória no seio da matriz, emprestando às camadas um aspecto maciço. Muito poucas vezes, são observadas imbricações do tipo $a(\mathrm{p}) a(\mathrm{i})$. A geometria dos corpos que compõem essa litofácies é, em geral, muito irregular, ou com menos frequência, em lobos ou tabular.

As características da litofácies $\mathrm{Cmf}$, descritas acima, apontam para uma deposição por fluxos de detritos verdadeiros (Middleton \& Hampton 1976), também denominados de fluxos de detritos plásticos (Shultz 1984), dispersões coesivas de alta concentração (Fisher 1971) ou fluxos de detritos coesivos (Lowe 1982). Nesses fluxos, os clastos são suportados pelo efeito de empuxo ("buoyance") favorecido pela elevada coesão da mistura água-sedimento que compõe a matriz (Hampton 1979). Este efeito de empuxo tem sua magnitude determinada pelo contraste de densidade entre os grãos mais grossos e a matriz bem como, pelo aumento da pressão nos poros causado pelo peso que a argila e os grãos 

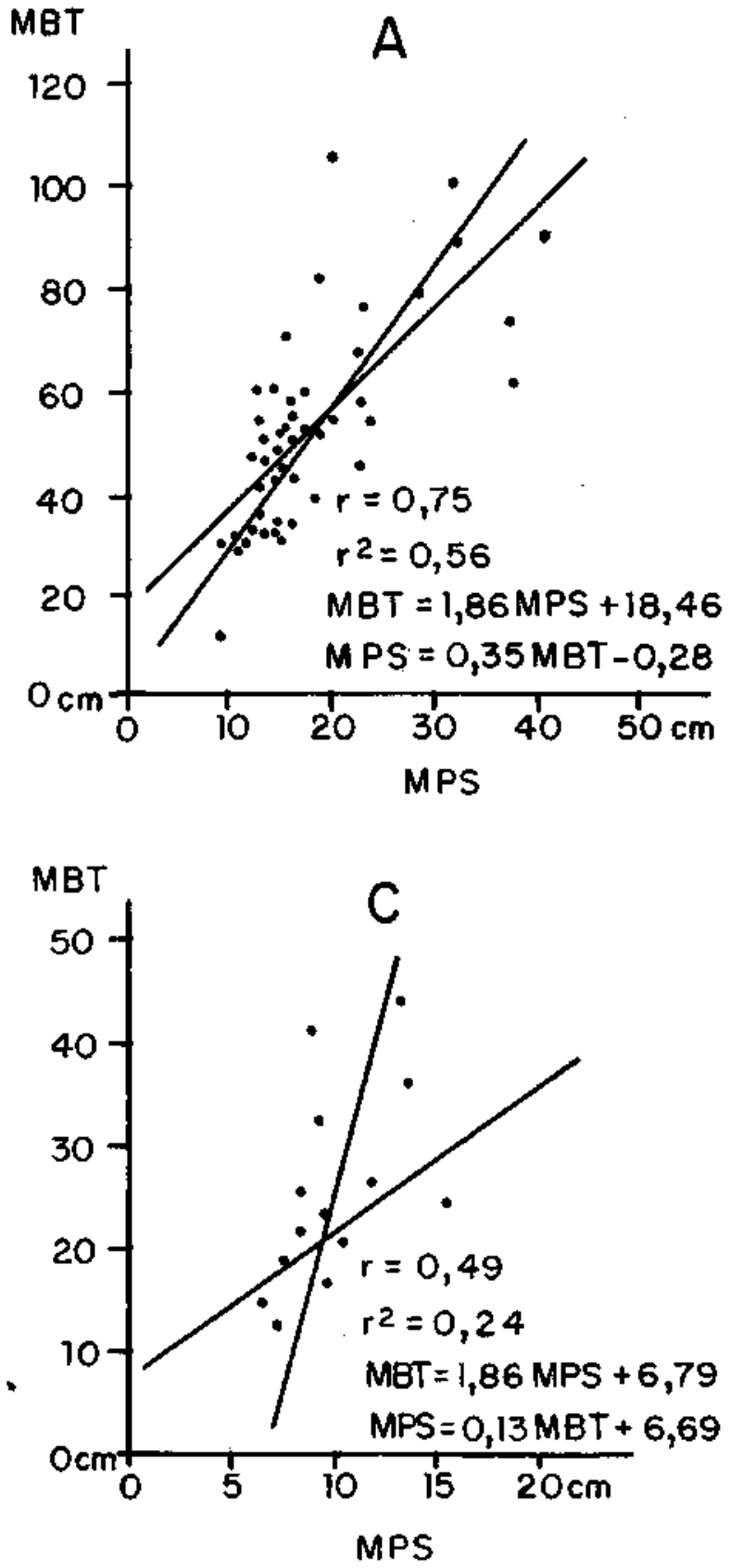

mais grossos transferem para a água. Diversos autores (Steel 1974, Middleton \& Hampton 1976 e Enos 1977), têm discutido o comportamento dos fluxos de detritos verdadeiros. Esses trabalhos sugerem que a preservação de seixos de argilitos, a ausência de superfícies erosivas e a orientação dos eixos maiores dos clastos paralelamente ao acamamento, observados em depósitos formados por esses fluxos, são evidências suficientes para atribuir aos mesmos um comportamento laminar. Nos conglomerados da litofácies Cmf são encontradas todas as evidências de fluxo laminar, acima citadas. Porém, é provável que nenhuma dessas feições seja, por si só, determinante para sustentar tal interpretaçã̃o. Assim é que clastos de argilitos ou clastos com alinhamento paralelo ao acamamento foram observados em outras litofácies da Formação Marizal, depositadas por fluxos onde se supôs a atuação de turbulência. A concentração baixa a moderada de clastos, associada à coesão da matriz, implica que o transporte ocorreu em um domínio viscoso (Shultz 1984), onde o fluxo se processou como um embolo rígido sobre uma zona de cisalhamento basal. A imobilização

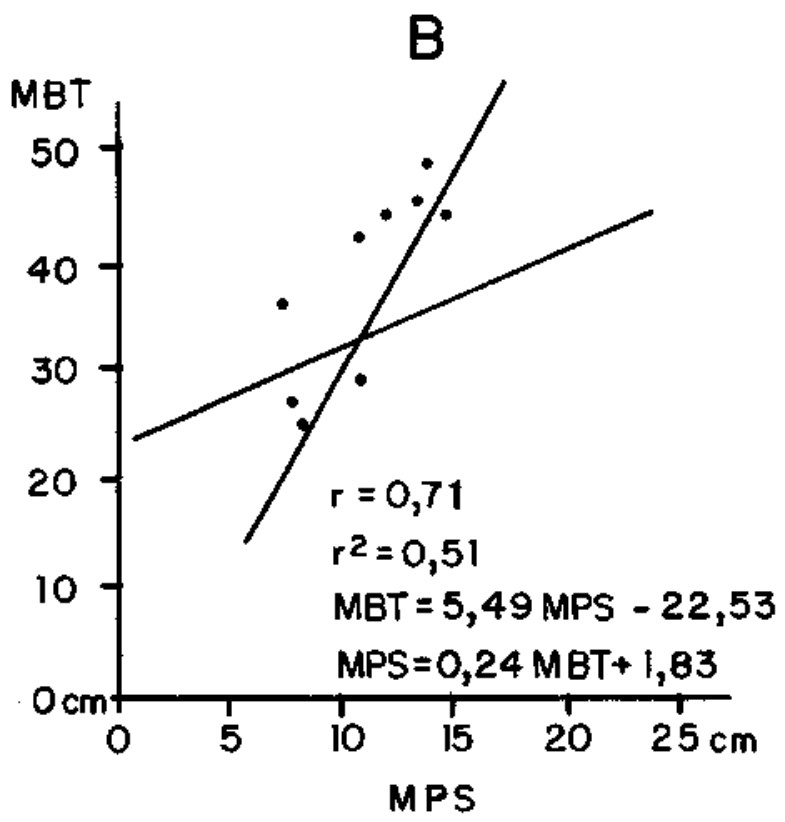

Figura 2 -Relações entre a espessura máxima das camadas (MBT) e o tamanho máximo das partículas (MPS) para as litofácies conglomeráticas da Formação Marizal. A. Litofácies Cmc-conglomerados maciços suportados por clastos; B. Litofácies Cma-conglomerados maciços suportados por matriz arenosa; $\boldsymbol{C}$. Litofácies Cec-conglomerados estratificados suportados por clastos e Cem-conglomerados estratificados suportados por matriz

Figure 2 - Relationships between maximum bed thickness (MBT) and maximum particle size (MPS) for the conglomeratic lithofacies of the Marizal Formation. A. Lithofacies Cmc-clast supported massive conglomerates; B. Lithofacies Cma-massive conglomerates supported by a sandy matrix; C. Lithofacies Cec-clast supported stratified conglomerates and Cem-matrix supported stratified conglomerates

tixotrópica dos fluxos de detritos (deposição) ocorre por "congelamento coesivo" ("cohesive freezing") (Lowe 1982), que é causado pela diminuição progressiva até o desaparecimento total da zona de cisalhamento basal, com o correspondente aumento da espessura do embolo rígido. Isso pode resultar de uma diminuição de declive e/ou do conteúdo de água do fluxo.

Conglomerados estratificados Esses conglomerados são representados pelas litofácies Cec-conglomerados estratificados suportados por clastos e Cem-conglomerados estratificados suportados pela matriz, que ocorrem em íntima associação (Prancha 1D) e possuem muitas feições em comum. Ambas as litofácies são constituídas por seixos e calhaus angulosos a bem arredondados, e de esfericidade baixa a alta. Na sua composição tem-se quartzo, feldspato e rochas quartzo-fedspáticas que perfazem entre 70 e $90 \%$ do total de clastos. Em proporções menores aparecem fenoclastos de siltito e lamito. Na litofácies $\mathrm{Cec}$, a matriz é bem selecionada, constituída por areia fina a média, em grãos 
subangulosos a subarredondados, formada por quartzo seguido por feldspato caulinizado, com mica aparecendo em quantidade inferior a $1 \%$. Na litofácies Cem, a matriz apresenta-se mal selecionada, variando de areia fina a grossa, com grãos angulosos a subarredondados, formada por feldspato caulinizado e, secundariamente, por quartzo. As camadas que constituem essas litofácies podem ser tabulares ou lenticulares e apresentar contatos basais erosivos ou transicionais. A espessura individual dos leitos varia de 8 a $70 \mathrm{~cm}$, com continuidade lateral da ordem de dezenas de metros. Os conglomerados apresentam fábrica bem desenvolvida, mostrando clastos achatados com os planos "ab" alinhados em paralelo com o acamamento e exibindo imbricação do tipo $a(i) b(i)$. Tanto gradações normal como inversa são observadas, mas camadas sem gradação também estão presentes. A espessura máxima das camadas e o tamanho máximo dos grãos apresentam um coeficiente de correlação de 0,49 (Fig. 2C), evidenciando uma fraca relação entre esses dois parâmetros. Interestratifícados com os conglomerados, aparecem camadas de arenitos finos a médios, com seixos e calhaus imersos, e arenitos conglomeráticos, ambos constituídos de quartzo, feldspato caulinizado e mica. Esses arenitos podem apresentar-se maciços ou exibir feições tais como laminação plano-paralela e estratificações cruzadas, além de estruturas de escavação e preenchimento.

Os conglomerados estratifícados são interpretados como sendo depósitos de barras longitudinais fluviais, formadas em períodos de inundações (Smith 1974, Hein \& Walker 1977, Miall 1977, Feyter \& Molenaar 1984). Todd (1989), baseado em estudos na Formação Trabeg (Devoniano, Irlanda) e em revisão bibliográfica, sugere que esses depósitos conglomeráticos são gerados por fluxos de detritos de domínio inercial e comportamento pseudolaminar (Postma et al, 1988), em um processo denominado por Lowe (1982) de tapete de tração.

Os tapetes de tração ocorrem em rios cascalhosos com leitos escarpados e/ou sujeitos a inundações de alta magnitude. Todd (1989) propõe a expressão "inundações de correntes de alta densidade" para fluxos em canais fluviais nos quais se desenvolvem esses tapetes. Segundo esse autor, eles podem ser gerados de duas maneiras: 1. pela adição gradativa de clastos do leito para uma carga de leito de - baixa densidade durante um estágio de subida ou descida do nível da água em uma inundação rápida. A partir de um determinado momento, a concentração de clastos atinge um valor tal, que a colisão inercial entre os mesmos passa a predominar. O tapete cascalhoso de alta densidade assim desenvolvido corresponde então a um "fluxo de grãos" cascalhosos conduzidos pela corrente, ou seja, a um tapete de tração; 2. a partir da suspensão de sedimentos cascalhosos, durante inundações de alta magnitude. Nesse caso, quando a velocidade de cisalhamento torna-se constante, ou começa a decrescer, os cascalhes podem se concentrar na base do fluxo, dissociando-se completamente da corrente turbulenta sobrejacente. A turbulência na camada basal é inibida pela concentração de clastos e o fluxo torna-se laminar. A partir daí, a concentração de clastos e a formação do tapete de tração processam-se de modo semelhante ao descrito para o caso anterior. $\mathrm{O}$ desenvolvimento do tapete de tração causa uma bipartição do fluxo, onde se forma uma camada basal altamente concentrada em clastos, e uma camada superior turbulenta e menos viscosa. A maioria dos clastos maiores é transportada no fluxo basal altamente concentrado, ou em suspensão, na parte inferior do fluxo turbulento. Esses clastos são conduzidos pelo arrasto exercido pelo fluxo turbulento superior e mantêm o eixo "a" imbricado, quando os seus centros de massa permanecem abaixo da descontinuidade reológica gerada. Quando os centros de massa se situam acima dessa interface, a imbricação gerada é do tipo $a(i) b(i)$ (Postma et al 1988). O suporte dos clastos é promovido provavelmente pela combinação de três mecanismos: 1. o levantamento por empuxo ("bouyant lift"), resultante do deslocamento pelos clastos cascalhosos de todo o sedimento do tapete, incluindo os próprios clastos (Hampton 1979); 2. a pressão dispersiva, provocada pelo choque entre os grãos e que atua quando as taxas de cisalhamento são altas; 3. a decantação retardada ("hindered settling"), devida aos contatos, grão a grão, quase estáticos e que é efetiva nos estágios em que as taxas de cisalhamento são baixas. A imobilização dos tapetes de tração (deposição) ocorre com a diminuição da profundidade do fluxo e/ou da inclinação do leito, que resulta no decréscimo do cisalhamento aplicado, que atinge uma magnitude menor do que a requerida para a manutenção do fluxo (Lowe 1982, Postma et al 1988, Todd 1989). Sendo os tapetes de tração transportados como fluxos de massa, seus depósitos podem apresentar várias feições em comum com os fluxos de detritos. Nos conglomerados estratifícados da Formação Marizal, por exemplo, foram observados intraclastos de siltitos, clastos com eixo maior disposto na vertical, e clastos muito grandes isolados, que são, portanto, características condizentes com a interpretação aventada para o processo de deposição dos mesmos.

CONCLUSÕES Na Formação Marizal foram identificadas cinco litofácies conglomeráticas, a partir do formato dos corpos que constituem as camadas individuais e das feições observadas internamente nesses corpos, tais como: laminação; orientação dos clastos (imbricação); disposição do eixo maior; presença de clastos excepcionalmente grandes, isolados; modo de sustentação dos clastos e o tipo da matriz dos conglomerados.

Três litofácies pertencem aos conglomerados maciços. As duas primeiras representadas pelas litofácies Cmc-conglomerados maciços suportados por clastos e Cma-conglomerados maciços suportados por matriz arenosa, foram interpretadas como sendo resultantes da deposição por fluxos de detritos pseudoplásticos. Eles diferem dos depósitos formados por fluxos de detritos ditos verdadeiros, por possuírem algumas feições normalmente associadas à deposição aquosa, tais como, o formato canalizado das camadas e a pequena quantidade de argila na matriz. A terceira, corresponde à litofácies Cmf-conglomerados maciços suportados por finos, tem características que apontam para uma deposição a partir dos chamados fluxos de detritos verdadeiros. Entre elas estão a grande quantidade de finos na matriz que sustenta os clastos, demonstrando um fluxo deposicional com um alto limite elástico, com o transporte ocorrendo em um domínio viscoso. A concentração de clastos, observada em algumas camadas dessa litofácies, caracteriza a presença de um embolo rígido, típico dos fluxos de detritos verdadeiros.

Com relação aos conglomerados estratifícados, eles são interpretados como produtos deposicionais de tapetes de tração cascalhosos, conduzidos pela corrente, em inundações de alta magnitude, ocorrendo em canais proximais rasos, de forte gradiente e baixa sinuosidade. Esses tapetes são conduzidos por fluxos de domínio inercial e são caracterizados por uma bipartição em duas camadas reologicamente diferenciadas pela concentração de clastos.

Agradecimentos Os autores agradecem aos professores Abílio C.S.P. Bittencourt e José M.L.Dominguez pela revisão do texto e versão do resumo para o inglês, respectivamente, e a um revisor anônimo cujas observações muito contribuíram para a clareza do texto. Agradecimentos são extensivos a Daniel S. Borges Filho, pela confecção dos desenhos. 


\section{REFERÊNCIAS BIBLIOGRÁFICAS}

BLUCK, B. J. 1967. Deposition of some Upper Old Red sandstone conglomerates in the Clyde area: a study in the significance of bedding. Scott. Jour., 3:139-167.

ENOS, P. 1977. Flow regimes in debris flow. Sedimentology, 24:132-142.

FEYTER, A. J. \& MOLENAAR, N. 1984. Messinian Fanglomerates: the Colobacci Formation in the Piatrarubbia Basin, Italy. Jour. Sed. Pet. 54:746-758

FISHER, R.V. 1971. Features of coarse-grained, high-concentration fluids and their deposits. Jour. Sed. Pet.,41:916-927.

GIGNONE, J. I. 1978. Geologia dos sedimentos fanerozóicos do Estado da Bahia. In: INDA, H.A.V. ed. Geologia e Recursos Minerais do Estado da Bahia-Textos Básicos, v. 1. Salvador-Bahia, SME/CPM. p. 24-117.

GLÕPPEN, T.G. \& STEEL, RJ. 1981. The deposits, internal structure and geometry in six alluvial fan-fan delta bodies (Devonian, Norway) - a study in the significance of bedding sequence in conglomerates. In: ETHRIDGE, F.G. \& FLORES, R.M. eds. Recent and ancient nonmarine depositional environment: models for exploration. Soc. Econ. Paleont. Mineral., Special Publ. 31. p.49-69.

HAMPTON, M.A. 1979. Buoyance in debris flow. Jour. Sed. Pet. 49:753-758.

HARMS, J.C.; SOUTHARD, J.B.; SPLARING, D.R. \& WALKER, R.G. 1975. Depositional environment as interpreted from primary sedimentary structures and stratification sequences. Soc. Econ. Paleont. Mineral., Short Course 2. 161p.

HEIN, F.J. \& WALKER, R.G. 1977. Bar evolution and development of stratification in gravelly, braided, Kicking River, British Columbia. Can. Jour. Earth. Sci., 14:562-570.

LARSEN.V. \& STEEL, R.J. 1978. The sedimentary history of a debris flow-dominated alluvial fan: a study of a textural inversion. Sedimentology, 25:37-59.

LEWIS, D.W. ; LAIRD, M.G. \& POWELL, R.D. 1980. Debris flow deposits of early Miocene age, Deadman Streem, Maelborough, New Zeland. Sediment. Geol, 27:37-59.

LIMA, C.C.U. 1991. Reconstrução arquitetural da Formação Marizal na Bacia do Reôncavo, Bahia, Brasil. Dissertação de Mestrado, UFBA. 115 p. (inédito).

LIMA, C.C.U. \& VILAS BOAS, G.S. 1990. Elementos arquiteturais da Formação Marizal nas proximidades de Camaçari-BA. In: CONGR. BRAS. GEOL., 36 Natal, 1990. Boletim de Resumos...Na $|a|$, SBG. p. 21

LINDHOLM, R. C. 1987. A practical approach to sedimentology. London, Allen \& Unwin. 276p.

LOWE, D.R. 1982. Sediment gravity flows: II, Depositional models with special reference to the deposits of high-density turbidity currents. Jour. Sed. Pet., 52:279-297.
MIALL, A.D. 1977. A review of the braided river depositional environment. Earth Sci. Rev., 13:1-62.

MIALL, A.D. 1978. Lithofacies types and vertical profiles models in braided rivers deposits: a summary. In: MIALL, A.D. ed. Fluvial Sedimentology. Can. Soc. Petrol. Geol., Memoir 5. p 597-604.

MIDDLETON, G.V. \& HAMPTON, M.A. 1976. Subaqueous sediment transport and deposition by sediment gravity flows. In: STANLEY D.J. \& SWIFT, D.J.P. eds. Marine transport and environmental management. New York, John Wiley, p. 197-218.

NEMEC, W. \& STEEL, R.J. 1984. Aluvial and coastal conglomerates:their significant features and some comments on gravelly mass-flow deposits. In:KOSTNER, E.H. \& STEEL, R.J. eds. Sedimentology of gravels and conglomerates. Can. Soc. Petrol. Geol., Memoir 10. p. $1-31$.

POSTMA, G.; NEMEC, W. \& KLEINSPEHN, K.I. 1988. Large floating clasts in turbidites: a mechanism for their emplacement. Sediment. Geol., 58:47-61.

POWERS, M.C. 1953. A new roundness scale for sedimentary particles. Jour. Sed. Pet., 23:117-119.

SCHULZ, A.W. 1984. Subaerial debris flow deposition in the Upper Paleozoic Cutler Formation, Western Colorado. Jour. Sed. Pet. 54:759-772.

SMITH, A.W. 1974. Sedimentology and bar formation in the upper Kicking Horse River, a braided outwash streem.Jour. Geol., 82:205-224.

STEEL, R.J. 1974. New Red Sandstone flood plain and piedmont sedimentation in the Hebridian Province, Scotland. Jour. Sed. Pet 44:336-357.

TANNER, W.F. 1969. The particle size (sic) scale. Jour. Sed. Pet., 39:809-812

TODD, S.P. 1989. Streem-driven, high-density gravelly traction carpets: possible deposits in the Trabeg Conglomerate Formation, SW Ireland and some theoretical considerations of their origin. Sedimentology, 36:513-530

VIANA, C.F.; GAMA Jr., E.G.; SIMÕES, LA.; MOURA, J.A.; FONSECA, JR \& ALVES, R J 1971. Revisão estratioráfica da Bacia do Recôncavo/Tucano. Boi. Técnico da Petrobrás, 14:157-192.

MANUSCRITO A824

Recebido em 22 de dezembro de 1994 Revisão do autor em 13 de junho de 1996 Revisão aceita em 17 de junho de 1996 